\title{
Article
}

\section{Depression Mediates the Relationship between Childhood Trauma and Internet Addiction in Female but Not Male Chinese Adolescents and Young Adults}

\author{
Xue Dong ${ }^{1,2, *}$, Ruxin Zhang ${ }^{3}{ }^{(}$, Simon Zhornitsky ${ }^{2}$, Thang M. Le ${ }^{2}$, Wuyi Wang ${ }^{2}$, Chiang-Shan R. Li ${ }^{2,4,5}$ \\ and Sheng Zhang ${ }^{2, *}$ \\ 1 Youth Mental Health Education Center, Department of Psychology, Shaanxi University of Science \& \\ Technology, Xi'an 710021, China \\ 2 Department of Psychiatry, Yale University School of Medicine, New Haven, CT 06519-1109, USA; \\ simon.zhornitsky@yale.edu (S.Z.); thang.le@yale.edu (T.M.L.); wuyi.wang@yale.edu (W.W.); \\ chiang-shan.li@yale.edu (C.-S.R.L.) \\ 3 Department of Economics and Management, Xi'an University of Technology, Xi'an 710054, China; \\ 1200510001@stu.xaut.edu.cn \\ 4 Department of Neuroscience, Yale University School of Medicine, New Haven, CT 06519-1109, USA \\ 5 Interdepartmental Neuroscience Program, Yale University, New Haven, CT 06519-1109, USA \\ * Correspondence: dongxue@sust.edu.cn (X.D.); sheng.zhang@yale.edu (S.Z.); Tel.: +86-159-2990-5919 (X.D.); \\ +86-120-3974-7310 (S.Z.)
}

\section{check for}

updates

Citation: Dong, X.; Zhang, R.; Zhornitsky, S.; Le, T.M.; Wang, W.; Li, C.-S.R.; Zhang, S. Depression Mediates the Relationship between Childhood Trauma and Internet Addiction in Female but Not Male Chinese Adolescents and Young Adults. J. Clin. Med. 2021, 10, 5015. https://doi.org/10.3390/jcm10215015

Academic Editors: Kirsi Honkalampi and Emmanuel Andrès

Received: 30 August 2021

Accepted: 26 October 2021

Published: 28 October 2021

Publisher's Note: MDPI stays neutral with regard to jurisdictional claims in published maps and institutional affiliations.

Copyright: (c) 2021 by the authors Licensee MDPI, Basel, Switzerland. This article is an open access article distributed under the terms and conditions of the Creative Commons Attribution (CC BY) license (https:// creativecommons.org/licenses/by/ $4.0 /)$.

\begin{abstract}
Internet addiction is associated with a range of psychological risk factors such as childhood trauma and depression. Studies have also suggested sex differences in internet and other behavioral addictions. However, it remains unclear how childhood trauma, depression and internet addiction inter-relate differently between the sexes. A total of 1749 adolescents and young adults aged 12-27 participated in a survey of sociodemographic characteristics and standardized assessments to evaluate internet addiction (Internet Addiction Test), childhood trauma (Childhood Trauma Questionnaire) and depression (Beck Depression Inventory). Mediation and path analyses were used to examine the relationship between childhood trauma, depression and internet addiction. Internet-addicted females relative to males showed more severe depression but the control participants showed the opposite. Childhood trauma was associated with depression for both internet-addicted males and females; however, internet-addicted females but not males showed significant associations between depression and the severity of internet addiction as well as between childhood trauma and the severity of internet addiction. Further, in females, depression mediated the correlations between all types of childhood trauma and the severity of internet addiction. A path analysis suggested that sexual abuse and emotional neglect contributed most significantly to internet addiction when all types of childhood trauma were examined in one model. The findings suggest sex differences in the relationship between childhood trauma, depression and internet addiction. Childhood trauma contributes to internet addiction through depression only in females. The findings may guide future prevention and intervention strategies of internet addiction.
\end{abstract}

Keywords: internet addiction; depression; childhood trauma; adolescents; young adults

\section{Introduction}

Internet addiction is defined as the "inability to control internet using, leading to physical, psychological and social difficulties" and is growing in prevalence and severity [1]. The prevalence rate of internet addiction among adolescents and young adults has increased from $1.6 \%$ in 2005 [2] to $6.7 \%$ in 2010 [3], 10.6\% in 2015 [4] and $28.6 \%$ in 2020 due to the outbreak of COVID-19 [5,6]. Since the first diagnosis by Young [7] in 1995, internet addiction has received more clinical attention, particularly among adolescents and young adults who have spent significantly more time on smartphones and tablets. Internet 
addiction has been associated with depression, attention-deficit hyperactivity disorder [8], social anxiety disorder [9], hostility and aggression $[10,11]$ as well as poor academic performance [12]. Although drug addiction distinctly involves physical dependence [13], behavioral addiction-including internet addiction-shares many of the psychological manifestations including craving and withdrawal [14,15].

Adolescents and young adults appear to be the most susceptible to internet addiction $[16,17]$. The increasing prevalence of internet addiction has been associated with low emotional stability and poor self-regulation in adolescents [18,19]. Adolescents with internet addiction may manifest depression [20] and engage in internet use to cope with emotional distress as well as to seek pleasure, social connections and a sense of achievement [21]. In particular, adolescents spend significantly more time on the internet to establish and maintain social interactions compared with adults [22,23]. Understanding the psychological and social factors that contribute to the severity of internet addiction is of critical importance to public health.

Depression is frequently comorbid with internet addiction in adolescents and young adults [24]. With autoregressive cross-lagged modeling, a recent longitudinal study showed that the severity of internet gaming disorder and depression are reciprocally predictive in college students [25]. Childhood trauma contributes to the development of depression in adolescents [26-28]. Childhood trauma generally refers to emotional, physical and sexual abuse as well as emotional and physical neglect [29]. Exposure to childhood trauma is considered to be a major risk factor for psychosocial dysfunction including emotional dysregulation, depression and heightened reward seeking in association with internet addiction [30-32]. Earlier studies suggested that childhood physical abuse was a main predictor of internet addiction among high school students [33]. Through the severity of post-traumatic stress disorder, physical and emotional neglect were directly and indirectly associated with internet addiction [34]. More recently, studies have identified depression as a mediator between childhood emotional trauma and internet gaming disorder [35] and between cyber victimization [36] as well as negative life events [37] and internet addiction among adolescents. Further, alexithymia partially mediated the relationship between traumatic experiences and internet addiction among late adolescents [38,39]. Together, these studies suggest depression to be an important mediator linking childhood trauma and internet addiction [40]. However, it remains unclear how depression may mediate the relationship between childhood trauma and internet addiction differently for males and females.

Male adolescents have shown a higher prevalence rate of internet addiction and a more severe internet gaming disorder relative to females [41-43]. Conversely, females relative to males demonstrated a more significant association between attention deficits and internet addiction as well as a higher risk of mobile phone addiction [44-46]. Other studies have provided evidence for potential sex-specific relations between childhood trauma and addictive behavior. Adolescent females with emotional difficulties such as subjective unhappiness or depressive symptoms had significantly higher risks of internet addiction relative to adolescent males with similar problems [47]. A higher number of traumatic experiences among late adolescent males but not females was predictive of internet addiction [38]. Moreover, female adolescents showed twice the likelihood of developing depression than male adolescents [48,49]. Together, these studies suggest the importance of considering sex differences in investigating the psychological factors of internet addiction and the relationship between childhood trauma, depression and internet addiction.

To this end, we conducted a large-scale cross-sectional study to investigate sex differences in the relationship between childhood trauma, depression and internet addiction in adolescents and young adults. We assessed childhood trauma with the Childhood Trauma Questionnaire (CTQ) and depression with the Beck Depression Inventory (BDI-II) in both internet-addicted and control participants. We employed mediation and path analyses to evaluate how depression may mediate the relationship between childhood trauma and the 
severity of internet addiction differently in males and females as assessed by the Internet Addiction Test (IAT). We also examined whether specific subtypes of childhood trauma may play a more significant role conducive to depression and internet addiction.

\section{Methods}

\subsection{Participants}

An online cross-sectional survey was conducted on adolescents and young adults in China between March and April 2020 and we invited 5717 regular internet users to participate in our study. A total of 1824 participants took part in the survey and the response rate was $31.9 \%$. We excluded individuals with a dependence on psychoactive substances in order to control the addiction effect other than the internet. However, individuals with nicotine dependence were not excluded as nicotine dependence was common in our samples with and without internet addiction. None of our 1824 participants showed any psychoactive substance use; thus, we did not exclude anyone. Further, we also excluded individuals with a current or past history of psychotic disorders as these disorders are known to have a cognitive and/or emotional dysfunction with unknown effects on our study. Seventy-five participants were excluded from the data analyses because of a current or past history of psychotic disorders. Finally, the data of 1749 participants $(877$ or $50.1 \%$ males) aged 12-27 (18.4 \pm 1.9 , mean $\pm \mathrm{SD})$ years were analyzed in the current study (Figure 1).

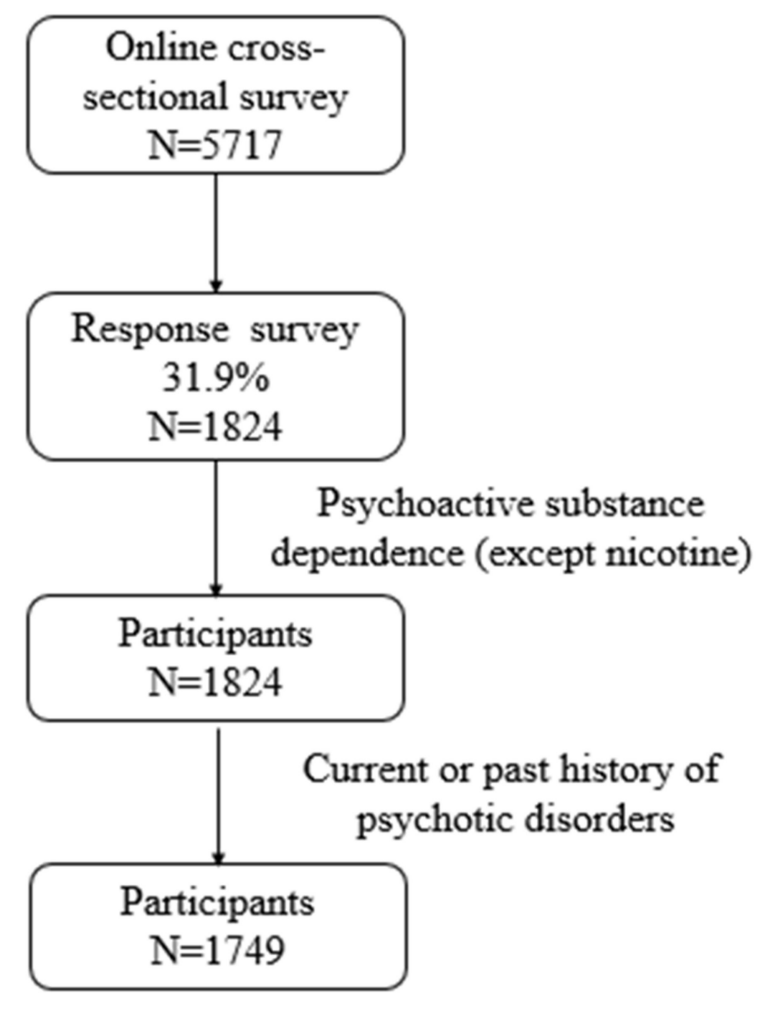

Figure 1. Flowchart of the selection of study participants.

All subjects were physically healthy with no major medical illnesses or current use of prescription medications. None reported having a history of a head injury or neurological illness. Sociodemographic characteristics including age, sex, education level, race and academic achievement were included in the survey. Academic achievement was assessed through a self-reported cumulative grade point average ranging from 1.50 to 5.00 for the previous semester, which was used as a categorical variable (Very good: 4.50-5.00; Good: 4.00-4.50; Moderate: 3.50-4.00; Poor: 1.50-3.50). The research was conducted according to a protocol approved by the Ethics Committee of Shaanxi University of Science and 
Technology. All participants gave their informed consent and parental or guardian consent was obtained for students under 18 years.

\subsection{Measures of Internet Addiction, Depression and Childhood Trauma}

Internet Addiction Test (IAT): The IAT (1998) has 20 items, each rated on a six-point Likert scale ranging from 0 (not at all) to 5 (always), to assess the degree to which internet use affected daily lives. A higher score indicated a higher degree of internet addiction: normal: 0-30; mild: 31-49; moderate: 50-79; and severe: $80-100$. This measure has been widely used around the world in studies investigating internet addiction and has been validated in many populations such as the United States [50], French [51], German [52], Polish [53], Spanish [54], Greek [55], Arabic [56], Vietnamese [57], Indonesian [58], Indian [59], Pakistani [60], Thai [61] and Korean [62] as well as Chinese [63]. A more recent review and meta-analysis study suggested that the IAT had an acceptable internal consistency, test-retest reliability and convergent validity among a total of 25 studies including 18,421 subjects [64]. Based on previous studies, we employed a cut-off score of $\geq 50$ to identify individuals with internet addiction according to Young's criteria [65-69]. The current sample comprised 391 (195 males and 196 females) individuals with internet addiction and 1358 (682 males and 676 females) controls. In this study, the factor loading of each item was between $0.777-0.881$ and Cronbach's $\alpha$ was 0.870 , which had a high reliability and validity.

Childhood Trauma Questionnaire (CTQ): A retrospective measure of childhood trauma [70], the CTQ has 28 items to assess traumatic life experiences during childhood and adolescence including emotional abuse, emotional neglect, physical abuse, physical neglect and sexual abuse. Each item is ranked from 1 (never) to 5 (very often) with a higher score indicating a higher severity of childhood trauma. The CTQ has shown an excellent test-retest validity and internal consistency [71].

Beck Depression Inventory (BDI-II): The BDI-II consists of 21 items addressing the symptoms of depression such as weight loss, irritability, hopelessness, suicide ideation, self-guilt and a lack of energy during the previous two weeks [72], each of which has four self-evaluative statements scored from 0 to 3 . Greater scores indicate a greater depression severity. The BDI-II scale has been shown to have good internal reliability, consistency and validity [73].

\subsection{Statistical Analyses}

We performed statistical analyses using SPSS 19.0 software. We conducted an $\chi^{2}$ test to analyze the race and academic success variables and a two-way ANOVA (grouped by sex) for all other variables. Using MATLAB, we performed a Pearson correction analysis for the BDI, IAT and CTQ scores with age as a covariate and mediation analyses using the toolbox M3. Using AMOS 21.0, we performed path analyses based on structural equation modeling. The details can be found in the "Mediation and Path Analyses" section. The $\chi^{2}$ test and ANOVA model as well as the mediation and path analyses were evaluated at $p<0.05$. The Pearson correction results were evaluated at a corrected threshold of $p=0.05 /(1+6+6)=0.0038$ considering a multiple comparison and $p<0.05$ as a marginal correlation.

\subsection{Mediation and Path Analyses}

We performed mediation analyses [74], using the toolbox M3 (https:/ / github.com/ canlab/MediationToolbox/tree/master/mediation_toolbox) to examine how depression mediated the relationship between childhood trauma (CTQ and subscores) and internet addiction. In a mediation analysis, the relation between the independent variable $X$ and the dependent variable $Y$, i.e., $X \rightarrow Y$, was tested to see if it was significantly mediated by a variable, $\mathrm{M}$. The mediation test was performed by employing three regression equations [74]:

$$
\begin{gathered}
\mathrm{Y}=\mathrm{i}_{1}+\mathrm{cX}+\mathrm{e}_{1} \\
\mathrm{Y}=\mathrm{i}_{2}+\mathrm{c}^{\prime} \mathrm{X}+\mathrm{bM}+\mathrm{e}_{2}
\end{gathered}
$$




$$
\mathrm{M}=\mathrm{i}_{3}+\mathrm{aX}+\mathrm{e}_{3}
$$

where a represents $X \rightarrow M, b$ represents $M \rightarrow Y$ (controlling for $X$ ), $c^{\prime}$ represents $X \rightarrow Y$ (controlling for $M$ ) and $c$ represents $X \rightarrow Y$. The constants $i_{1}, i_{2}$ and $i_{3}$ are the intercepts and $e_{1}$, $\mathrm{e}_{2}$ and $\mathrm{e}_{3}$ are the residual errors. In the literature, $\mathrm{a}, \mathrm{b}, \mathrm{c}$ and $\mathrm{c}^{\prime}$ were referred to as the path coefficients or simply the paths [74] and we followed this notation. Variable M is said to be a mediator of the correlation $\mathrm{X} \rightarrow \mathrm{Y}$ if $\left(\mathrm{c}-\mathrm{c}^{\prime}\right)$, which is mathematically equivalent to the product of the paths $a \times b$, is significantly different from zero [74]. If the product a $\times b$ and the paths $a$ and $b$ are significant, one concludes that $X \rightarrow Y$ is mediated by $M$. In addition, if path $c^{\prime}$ is not significant, there is no direct connection from $X$ to $Y$ and that $X \rightarrow Y$ is completely mediated by $\mathrm{M}$. Note that path $\mathrm{b}$ is the relation between $\mathrm{Y}$ and $\mathrm{M}$ controlling for $\mathrm{X}$ and should not be confused with the correlation coefficient between $\mathrm{Y}$ and $\mathrm{M}$.

A path analysis was performed to identify the relationships between childhood trauma, depression and internet addiction using structural equation modeling (SEM). SEM is a multivariate analysis to examine structural relationships [75], combining a confirmatory factor analysis with a multiple regression and enabling hypothesis testing about multiple relations among observed and latent variables [76]. SEM has the advantage of simultaneously estimating multiple and mutual dependencies, identifying latent variables for these relationships and returning direct and indirect effect sizes. Importantly, SEM can handle multiple dependent variables simultaneously. As the CTQ subscores were highly correlated, we employed SEM to include the BDI, IAT and all CTQ subscores in one model to account for the inter-relationship among the CTQ subscores. SEM has been widely applied to the research of internet addiction [77-79].

\section{Results}

\subsection{Sociodemographic and Clinical Variables}

The prevalence of internet addiction in this sample was $22.3 \%(391 / 1749)$ based on Young's criteria of an IAT score $\geq 50$. Of the 391 individuals in the internet-addicted group, $49.9 \%(195 / 391)$ were males and $50.1 \%(196 / 391)$ were females. The mean \pm standard deviation values of the clinical variables are shown in Figure 2 and the statistics of the group main effect, sex main effect and group by sex interaction effect are shown in Table 1. The internet-addicted vs. the control group exhibited a higher level of the IAT score, BDI score and CTQ total and all subscores (all $p<0.001$ ). In the sex main effect, the males showed a higher PA $(p<0.001)$, SA $(p<0.001)$, EN $(p<0.05)$ and PN $(p<0.001)$ but not IAT $(p=0.35)$, BDI $(p=0.86)$ and EA $(p=0.15)$ score compared with females. There was also a significant group by sex interaction for the IAT $(p<0.001)$, BDI $(p<0.001)$, PA $(p<0.001)$, SA $(p<0.01), \mathrm{EN}(p<0.001)$ and PN $(p<0.01)$ score but not for the CTQ total score $(p=0.75)$ and EA $(p=0.53)$. In the post-hoc analysis of sex difference, the male vs. the female controls showed a higher level of all variables (all $p<0.007)$. However, internet-addicted males vs. females showed a higher PA $(p<0.001)$ and SA $(p<0.001)$ but a lower BDI $(p=0.035)$ score. There was no difference for the other variables (all $p>0.063$ ). 


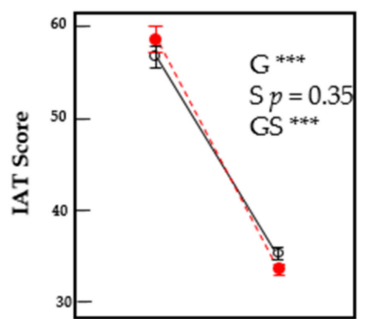

IA $\mathrm{HC}$
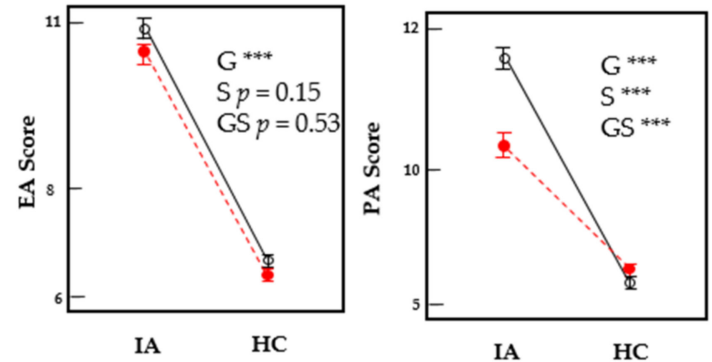

Female

Male o
IA = Internet-addicted $\mathrm{HC}=$ Health-control $\mathrm{G}=\mathrm{Group}$ $\mathrm{S}=\mathrm{Sex}$ $\mathrm{GS}=\mathrm{Group}^{*} \mathrm{Sex}$

*** $p<0.001$

** $p<0.01$

* $p<0.05$

Figure 2. Mean and error bar (SD) plot of the BDI, IAT and CTQ totals and subscores shown separately for internetaddicted males, internet-addicted females, control males and control females. Significant group effects by sex interaction are represented by the cross lines between the internet-addicted males-control males and the internet-addicted femalescontrol females.

Table 1. Sociodemographic and clinical variables in the internet-addicted (IA) and control groups.

\begin{tabular}{|c|c|c|c|c|c|c|c|}
\hline Characteristic & $\begin{array}{l}\text { Male IA } \\
(n=195)\end{array}$ & $\begin{array}{c}\text { Female IA } \\
(n=196)\end{array}$ & $\begin{array}{c}\text { Male } \\
\text { Control } \\
(n=682)\end{array}$ & $\begin{array}{l}\text { Female } \\
\text { Control } \\
(n=676)\end{array}$ & Group & Sex & $\begin{array}{l}\text { Group * } \\
\text { Sex }\end{array}$ \\
\hline Age & $18.68 \pm 1.78$ & $18.01 \pm 1.82$ & $18.49 \pm 1.94$ & $18.39 \pm 1.83$ & $\begin{array}{l}\mathrm{F}=0.81 \\
p=0.37\end{array}$ & $\begin{array}{c}\mathrm{F}=13.21 \\
p<0.001^{* * *}\end{array}$ & $\begin{array}{c}\mathrm{F}=7.19 \\
p=0.007\end{array}$ ** \\
\hline $\begin{array}{l}\text { Race } \\
\text { Han ethnicity } \\
\text { Other ethnicity }\end{array}$ & $\begin{array}{c}178(91.3 \%) \\
17(8.7 \%)\end{array}$ & $\begin{array}{c}188(95.9 \%) \\
8(4.1 \%)\end{array}$ & $\begin{array}{c}633(92.8 \%) \\
49(7.2 \%)\end{array}$ & $\begin{array}{c}627(92.8 \%) \\
49(7.2 \%)\end{array}$ & $\begin{array}{l}\chi^{2}=0.31 \\
p=0.575\end{array}$ & $\begin{array}{l}\chi^{2}=0.65 \\
p=0.419\end{array}$ & $\begin{array}{l}\chi^{2}=3.53 \\
p=0.317\end{array}$ \\
\hline \multicolumn{8}{|l|}{ Academic success } \\
\hline Very good & $18(9.2 \%)$ & $7(3.6 \%)$ & $54(7.9 \%)$ & $46(6.8 \%)$ & $x^{2}=25.17$ & $\chi^{2}=33.59$ & $\chi^{2}=61.61$ \\
\hline Good & $57(29.2 \%)$ & $64(32.7 \%)$ & $261(38.3 \%)$ & $276(40.8 \%)$ & $p<0.001^{* * *}$ & $p<0.001^{* * *}$ & $p<0.001^{* * *}$ \\
\hline Moderate & $78(40.0 \%)$ & $100(51.0 \%)$ & $280(41.1 \%)$ & $319(47.2 \%)$ & & & \\
\hline Poor & $42(21.5 \%)$ & $25(12.8 \%)$ & $87(12.8 \%)$ & $35(5.2 \%)$ & & & \\
\hline IAT & $57.40 \pm 6.53$ & $58.67 \pm 6.93$ & $35.91 \pm 6.38$ & $34.01 \pm 5.07$ & $\begin{array}{l}\mathrm{F}=4496.04 \\
p<0.001^{* * *}\end{array}$ & $\begin{array}{l}\mathrm{F}=0.86 \\
p=0.35\end{array}$ & $\begin{array}{c}\mathrm{F}=21.28 \\
p<0.001^{* * *}\end{array}$ \\
\hline BDI & $23.88 \pm 12.91$ & $26.53 \pm 11.87$ & $6.75 \pm 9.71$ & $3.92 \pm 3.28$ & $\begin{array}{l}\mathrm{F}=1592.42 \\
p<0.001\end{array}$ & $\begin{array}{c}\mathrm{F}=0.033 \\
p=0.86\end{array}$ & $\begin{array}{c}\mathrm{F}=30.27 \\
p<0.001^{* * *}\end{array}$ \\
\hline CTQ & $61.80 \pm 11.56$ & $58.20 \pm 11.06$ & $37.16 \pm 10.21$ & $33.23 \pm 5.87$ & $\begin{array}{l}\mathrm{F}=2263.62 \\
p<0.001^{* * * *}\end{array}$ & $\begin{array}{c}\mathrm{F}=52.18 \\
p<0.001 * * *\end{array}$ & $\begin{array}{c}\mathrm{F}=0.100 \\
p=0.75\end{array}$ \\
\hline EA & $10.92 \pm 3.79$ & $10.80 \pm 3.94$ & $6.70 \pm 2.26$ & $6.39 \pm 1.79$ & $\begin{array}{c}\mathrm{F}=861.57 \\
p<0.001^{* * *}\end{array}$ & $\begin{array}{l}F=2.04 \\
p=0.15\end{array}$ & $\begin{array}{c}\mathrm{F}=0.400 \\
p=0.53\end{array}$ \\
\hline PA & $11.34 \pm 3.48$ & $8.89 \pm 2.47$ & $5.91 \pm 1.72$ & $5.35 \pm 1.07$ & $\begin{array}{l}\mathrm{F}=1679.31 \\
p<0.001^{* * *}\end{array}$ & $\begin{array}{c}\mathrm{F}=190.19 \\
p<0.001^{* * *}\end{array}$ & $\begin{array}{c}\mathrm{F}=74.97 \\
p<0.001^{* * *}\end{array}$ \\
\hline SA & $10.86 \pm 4.18$ & $9.48 \pm 3.61$ & $5.84 \pm 2.19$ & $5.27 \pm 1.19$ & $\begin{array}{l}\mathrm{F}=1113.39 \\
p<0.001\end{array}$ & $\begin{array}{c}\mathrm{F}=48.97 \\
p<0.001^{* * *}\end{array}$ & $\begin{array}{c}\mathrm{F}=8.50 \\
p=0.004^{* *}\end{array}$ \\
\hline $\mathrm{EN}$ & $16.31 \pm 3.75$ & $16.70 \pm 3.70$ & $9.80 \pm 3.77$ & $8.45 \pm 2.41$ & $\begin{array}{l}\mathrm{F}=1520.52 \\
p<0.001^{* * *}\end{array}$ & $\begin{array}{c}\mathrm{F}=6.55 \\
p=0.011\end{array}$ & $\begin{array}{c}\mathrm{F}=21.15 \\
p<0.001^{* * *}\end{array}$ \\
\hline $\mathrm{PN}$ & $12.78 \pm 2.94$ & $12.71 \pm 2.54$ & $8.91 \pm 3.18$ & $7.77 \pm 2.54$ & $\begin{array}{c}\mathrm{F}=727.81 \\
p<0.001^{* * *}\end{array}$ & $\begin{array}{c}\mathrm{F}=13.90 \\
p<0.001^{* * *}\end{array}$ & $\begin{array}{c}\mathrm{F}=10.67 \\
p=0.0011^{* * *}\end{array}$ \\
\hline
\end{tabular}

Values are mean $\pm \mathrm{SD}$ or the actual number (percentage \%); IAT = Internet Addiction Test; BDI = Beck Depression Inventory; CTQ = Childhood Trauma Questionnaire; EA = emotional abuse subscale; PA = physical abuse subscale; $\mathrm{SA}=$ sexual abuse subscale; $\mathrm{EN}=$ emotional neglect subscale; $\mathrm{PN}=$ physical neglect subscale; statistically significant difference: $p<0.05^{*} ; p<0.01^{* *} ; p<0.001^{* * *}$. 


\subsection{Associations between the BDI, IAT and CTQ Scores in the Internet-Addicted Group}

We computed the Pearson correlations between the BDI, IAT and CTQ scores for the internet-addicted group with age as a covariate (Figure 3 ) and evaluated the results at a corrected threshold of $p=0.05 /(1+6+6)=0.0038$ considering for a multiple comparison. The BDI and IAT scores showed a positive correlation for females $\left(\mathrm{r}=0.45, p=3.89 \times 10^{-11}\right)$ but not males $(\mathrm{r}=0.03, p=0.72)$ and the sex difference of the correlations was confirmed by a slope test $(\mathrm{z}=-4.46, p<0.0001)$. For females, the IAT score was positively correlated with the CTQ total $(\mathrm{r}=0.33, p=0.000025)$ and the subscores of SA $\left(\mathrm{r}=0.41, p=2.67 \times 10^{-9}\right)$, EN $\left(r=0.38, p=4.09 \times 10^{-8}\right)$ and PN $(r=0.21, p=0.0037)$ as well as at a marginal level for EA $(\mathrm{r}=0.18, p=0.0099)$ and PA $(\mathrm{r}=0.18, p=0.011)$. For males, only the PA subscore showed a marginal correlation with the IAT score $(\mathrm{r}=0.15, p=0.036)$. The slope test showed sex differences for a BDI correlation with the CTQ total $(\mathrm{z}=-2.97, p=0.003)$ and SA $(z=-3.98, p=0.0001)$ and at a marginal level for the EN $(z=-2.74, p=0.0061)$ scores but not with the EA $(\mathrm{z}=-1.29, p=0.2)$, PA $(\mathrm{z}=-0.3, p=0.76)$ and PN $(\mathrm{z}=-0.81, p=0.42)$ scores. Further, the BDI score was correlated with the CTQ total and subscores for both females $\left(\mathrm{r}=0.58, p=1.08 \times 10^{-18}\right.$ for the total score; $\mathrm{r}=0.25, p=0.00033$ for $\mathrm{EA} ; \mathrm{r}=0.28$, $p=0.000058$ for PA; $\mathrm{r}=0.41, p=2.82 \times 10^{-9}$ for SA; $\mathrm{r}=0.62, p=1.71 \times 10^{-22}$ for $\mathrm{EN}$; and $\mathrm{r}$ $=0.4, p=5.12 \times 10^{-9}$ for PN) and males for the total score $\left(\mathrm{r}=0.5, p=6.43 \times 10^{-14}\right)$, SA $(\mathrm{r}=0.24, p=0.0009)$, $\mathrm{EN}\left(\mathrm{r}=0.56, p=4.47 \times 10^{-17}\right)$ and $\mathrm{PN}\left(\mathrm{r}=0.43, p=2.52 \times 10^{-10}\right)$ as well as at a marginal level for EA $(r=0.17, p=0.02)$ and PA $(r=0.14, p=0.048)$. The slope test showed no sex difference (all $p>0.062$ ).

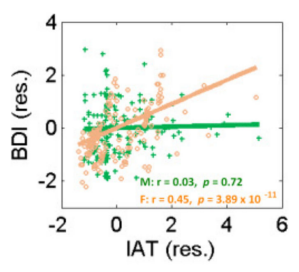

internet-addicted male

internet-addicted female
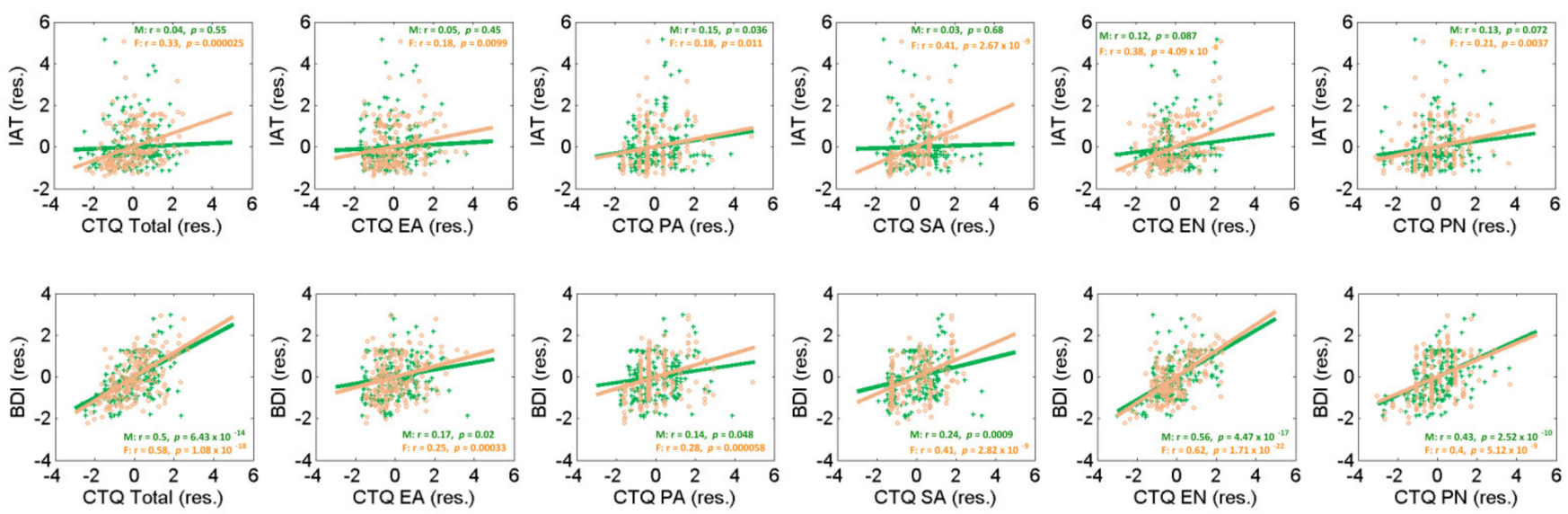

Figure 3. Linear regression of the BDI, IAT and CTQ totals and subscores shown separately for the internet-addicted males and females with age as a covariate. Each data point represents the residual after accounting for age. Green (crosses) and orange (circles) show the data points and regression lines for males and females, respectively.

\subsection{Mediation and Path Analyses for Female Internet-Addicted Individuals}

As the CTQ, BDI and IAT scores were pair-wise correlated for females with internet addiction, we conducted a mediation analysis to examine whether the BDI mediated the relationship between the CTQ total and five subscores and the IAT. The results showed that all models were significant with the BDI score mediating the correlation between the CTQ and IAT scores (Figure 4). Specifically, without the mediation of the BDI score, the CTQ total, EA, PA or PN were not correlated with the IAT ( $p=0.18,0.26,0.39$ and 0.66 , respectively) score, suggesting a complete mediation. 
(A)

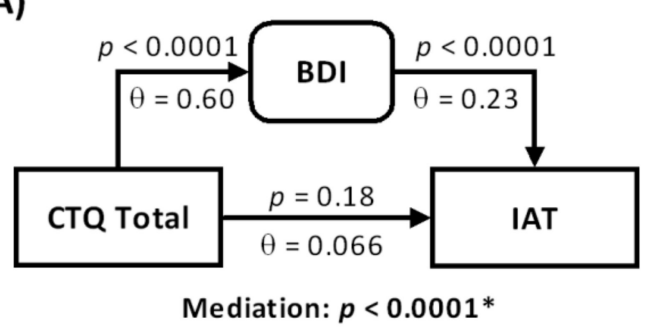

(C)

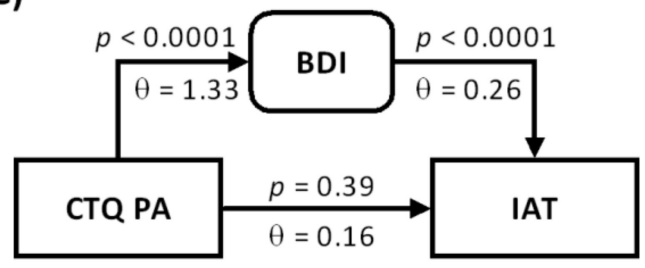

Mediation: $p=0.0006^{*}$

(E)

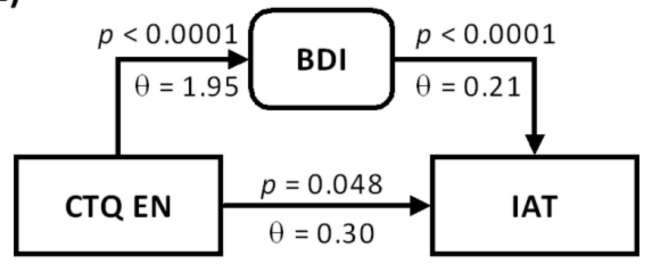

Mediation: $p<0.0001^{*}$
(B)

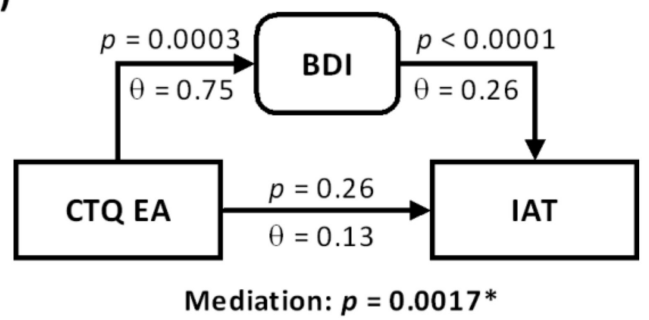

(D)

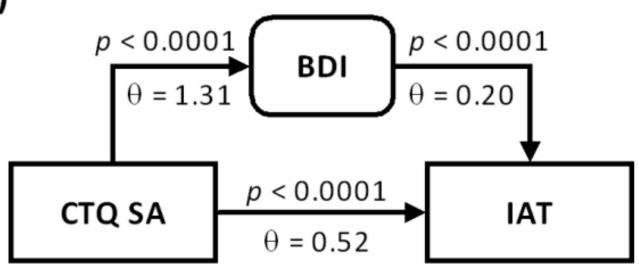

Mediation: $p=0.0001^{*}$

(F)

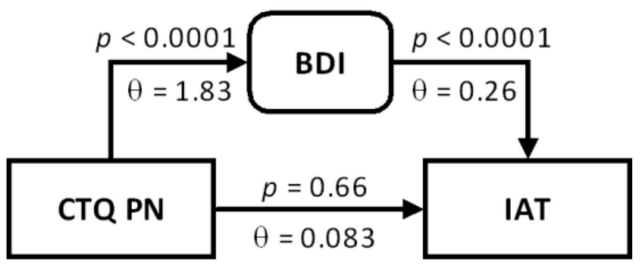

Mediation: $p<0.0001^{*}$

Figure 4. Mediation analysis of the BDI, IAT and CTQ totals (A) and subscores (B-F) in internet-addicted females. The $p$-values associated with mediation are for the path "a $\times b^{\prime \prime}$ (see Section 2.4). All models are significant, suggesting that the BDI mediated the relationship between the CTQ total/subscores and the IAT score. Specifically, the relationships of the CTQ total and the EA, PA and PN scores with the IAT were completely mediated by the BDI score.

We conducted a path analysis to include the BDI score, IAT score and all CTQ subscores in one model for internet-addicted females (Figure 5). The model showed that the BDI $(\beta=0.25, p<0.01)$, SA $(\beta=0.31, p<0.001)$ and $\mathrm{EN}(\beta=0.17, p<0.05)$ had significant positive effects on the IAT; SA $(\beta=0.23, p<0.001)$ and EN $(\beta=0.51, p<0.001)$ had significant positive effects on the BDI (Supplementary Table S1).

Based on the results of the path analysis, we used the Bootstrap method to test the mediation effect of the BDI in internet-addicted females. The result showed significant mediation effects of the BDI in the SA-IAT path $(\beta=0.11$, confidence interval $=(0.03,0.26)$, $p<0.05)$ and of the BDI in the EN-IAT path $(\beta=0.24$, confidence interval $=(0.07,0.42)$, $p<0.05)$ (Supplementary Table S2). 


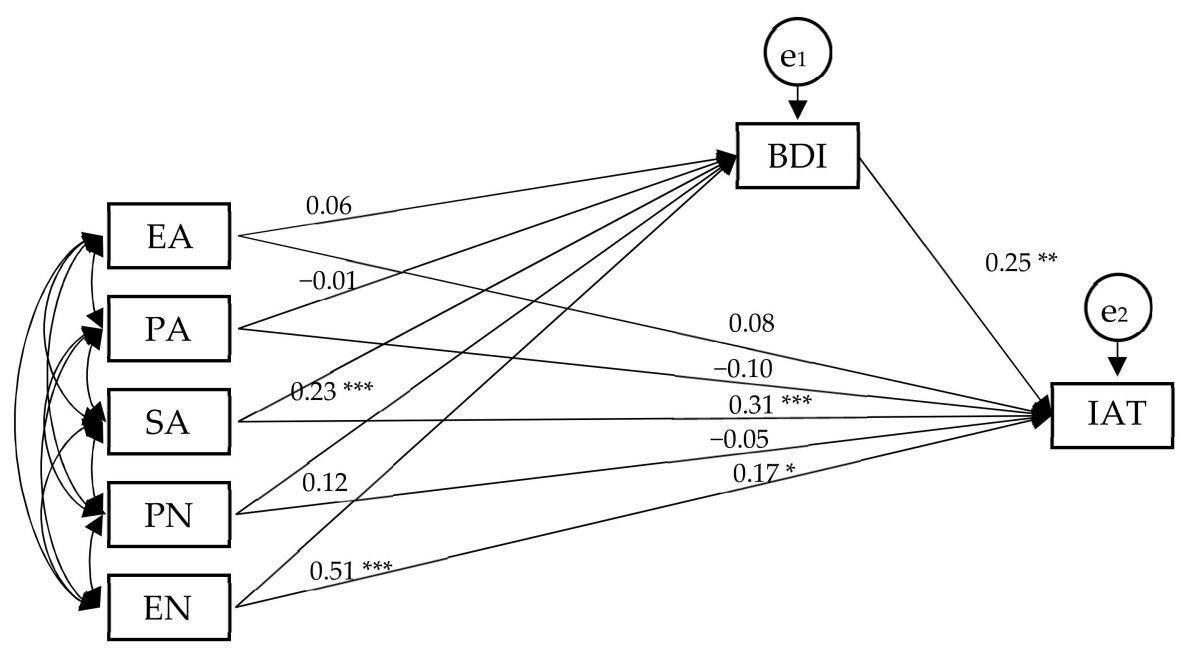

Figure 5. Path analysis of childhood trauma (CTQ subscores), the severity of depression (BDI score) and internet addiction (IAT score) for female internet-addicted individuals. EA = emotional abuse subscale; $\mathrm{PA}=$ physical abuse subscale; $\mathrm{SA}$ = sexual abuse subscale; $\mathrm{EN}$ = emotional neglect subscale; $\mathrm{PN}=$ physical neglect subscale. $\mathrm{e} 1$ and $\mathrm{e} 2$ represent the error terms of the BDI and IAT scores. The value on each path indicates the standardized coefficient. ${ }^{* * *}: p<0.001{ }^{* *}: p<0.01{ }^{*}: p<0.05$.

\section{Discussion}

We examined sex differences in the relationship between childhood trauma, depression and the severity of internet addiction among Chinese adolescents and young adults. Males showed a greater severity of internet addiction as well as most types of childhood trauma (except for emotional abuse) compared with females. Internet-addicted females showed more severe depression compared with internet-addicted males but the control males showed more severe depression compared with the control females. Childhood trauma was associated with depression for both internet-addicted males and females. However, internet-addicted females but not males showed significant associations between depression and internet addiction and between childhood trauma and the severity of internet addiction. Importantly, depression mediated the correlations between all types of childhood trauma when modeled separately as well as the severity of internet addiction in females. A path analysis further suggested that sexual abuse and emotional neglect contributed more significantly to internet addiction when all childhood trauma subtypes were examined together in one model. The findings suggested sex differences in the relationship between childhood trauma, depression and internet addiction. Childhood trauma is conducive to depression and, in turn, internet addiction only in females.

\subsection{Childhood Trauma Leads to Internet Addiction through Depression in Females but Not in Males}

Childhood trauma contributes to internet addiction in females but not males, despite more severe traumatic experiences of males during childhood. Internet addiction is consistent with childhood trauma among adolescents [80,81]. In addition, sex differences have frequently been observed in the research on the relationship between childhood trauma and addiction. For instance, childhood trauma is associated with a greater severity of gambling problems in pathological gamblers especially female gamblers [82]. A previous study showed that females who experienced childhood emotional neglect, physical and sexual trauma were more likely to develop an alcohol use disorder [83]. Females who reported experiencing child abuse and neglect were significantly more likely to have used illicit drugs compared with males who reported similar childhood trauma [84]. Childhood maltreatment was found to be significantly associated with alcohol problems for females but not males and childhood sexual abuse was found to predict substance abuse in females but not in males [85]. Thus, by showing a female-specific relationship between childhood 
trauma and internet addiction, the current findings extend this literature of sex differences to behavioral addiction.

Importantly, we observed that childhood trauma contributes to the severity of internet addiction via depression in females. An earlier study showed that childhood trauma had a significant impact on the internet gaming behaviors of adolescents among college students and both anxiety and depression significantly mediated the relationship between childhood trauma and internet gaming [40]. Another study showed that emotion dysregulation and depression mediated the association between adverse childhood experiences and the severity of food and social media addictions [86]. On the other hand, these studies did not examine sex differences and the current findings suggest the importance of considering sex differences in future research.

We showed that, of the subtypes of childhood trauma, sexual abuse and emotional neglect contributed more prominently to internet addiction through depression in females. Studies have reported greater effects of sexual abuse and emotional neglect on the mental health of females [87-90]. For instance, girls experiencing more severe emotional neglect and childhood maltreatment than boys significantly increased the likelihood of post-traumatic depression for all children but more severely for girls than for boys [89]. Childhood emotional neglect and adolescent depression were positively correlated even after controlling for other types of childhood maltreatment and sex moderated the relation between childhood emotional abuse and deviant peer affiliation with the relationship being stronger for girls than for boys [90]. Compared with those who did not experience childhood sexual abuse, females who experienced childhood sexual abuse reported greater levels of alcohol use and anxiety and the anxiety significantly mediated the association between childhood sexual abuse and alcohol abuse [91].

\subsection{Sex Difference of the BDI and Childhood Trauma}

We observed a higher BDI score in internet-addicted females vs. males but a lower BDI score in the control females vs. males. Further, the BDI positively correlated with the IAT score for internet-addicted females but not males. These findings suggested that a higher BDI score as observed in internet-addicted females might represent a consequence of internet addiction. In a three-year longitudinal study of Chinese adolescents, the severity of internet addiction predicted the occurrence of later depression but depression did not predict internet addiction in females whereas the reverse was true in males [92]. Another study showed that individuals with internet addiction vs. controls exhibited more severe depression and the interaction effect of depression by internet addiction was more severe in females than in males [93]. These, along with our findings, suggest that females are more vulnerable to the effects of internet addiction on the pathogenesis and/or progression of depression. Indeed, previous studies have typically found that females experience more depression than males [94-97] and are more likely to experience negative moods following victimization [98-101]. Thus, treatment for individuals with internet addictionparticularly females-should involve an effort to prevent the exacerbation of depression.

Previous studies from the United States and Turkey showed that females experienced more emotional and sexual abuse whereas males experienced more physical abuse [102-105]. Alcohol or other drug-dependent patients showed a higher frequency and higher intensity of childhood trauma compared with the controls and females showed a higher frequency of childhood trauma in all groups compared with males among a Brazilian clinical sample [26]. However, we found that males had higher levels of nearly all types of childhood trauma (except emotional abuse) compared with females, which was consistent with another study of Chinese adolescents [106]. In a large-scale $(n=15,890)$ cross-sectional survey of the children of rural-to-urban migrant workers in grades 4 to 9 in China, boys were more likely to experience trauma compared with girls [107]. Together, these findings suggest the importance of considering cultural differences in evaluating childhood trauma in adolescents. The culture justifying the use of corporal punishment or 
verbal reprimands by parents to discipline their sons, for instance, represents a relatively distinct experience of boys growing up in Chinese society [108].

\subsection{Strengths, Limitations and Conclusions}

The current study has three strengths. (1) We conducted a large-scale cross-sectional study to investigate sex differences in the relationship between childhood trauma, depression and internet addiction in Chinese adolescents and young adults; (2) we performed two models to evaluate how depression may mediate the relationship between childhood trauma and the severity of internet addiction and the path analysis model not only crossvalidated the findings from the mediation analysis model but also provided additional details by accounting for the inter-relationship among the CTQ subscores; (3) we examined the CTQ total and all subscores in our study.

A few limitations need to be considered for the study. First, the response rate of $31.9 \%$ was low. The main reason was that the adolescents and young adults in China were not in school due to COVID-19 when we performed our survey between March and April 2020. We were not able to give them a good explanation about the research and help them to complete the self-administered questionnaires in person. Due to being at home, a few of them may have had a low motivation to participate in our study. On the other hand, nearly half of our data were male $(50.1 \%)$, which suggested that our dataset was valid to examine the sex difference. Second, there was an age difference between sexes. Although we included age as a covariate in our analyses, we could not entirely rule out the effect of age on the current findings. Our survey was performed during the COVID-19 pandemic and we could not rule out the effect of the pandemic on depression and internet addiction. Thus, future studies are needed for subjects with a matched age between sex with a survey performed during a normal period. Third, the study was limited by the moderate sample size and cross-sectional design. We only explored the relationship between adolescent depression and internet addiction at one point in time. Longitudinal studies are needed to confirm the results of the present study. Fourth, our data comprised self-report items, which are known to be affected by various response biases. Future work should combine information from parents, teachers and psychologists to verify and further explore the relationships. Fifth, the prevalence of severe internet addiction among our sample was only $0.7 \%$. Previous studies found the prevalence rate of severe internet addiction to be $2.5 \%$ among high school students in South Korea [109], 2.0\% in Japan [110] and 6.44\% in first-year university students in China [111]. Thus, one should consider the possibility that the current cohort may not be a representative sample.

In conclusion, the present study is among the first to examine sex differences of the direct and indirect relationships between childhood trauma, depression and internet addiction. The severity of internet addiction of internet-addicted Chinese females but not males was associated with both depression and childhood trauma. Importantly, depression mediated the correlations between all types of childhood trauma and internet addiction. A path analysis further suggested a more significant role of sexual abuse and emotional neglect conducive to internet addiction. Overall, the findings highlighted the critical importance of considering sex as a biological variable when examining the relationship between childhood trauma, depression and internet addiction. In addition, our study confirmed the theoretical model of the effect of childhood trauma on internet addiction and highlighted that depression was an important trigger linking childhood trauma and internet addiction in females but not in males. Our findings have practical and important implications for managers and educators. Managers/educators may closely monitor the depressive state of their female employees/students with childhood trauma in order to reduce internet addiction. Our findings may support and guide more effective health promotion strategies in the treatment of internet addiction. 
Supplementary Materials: The following are available online at https: / www.mdpi.com/article/ $10.3390 / \mathrm{jcm} 10215015$ / s1, Table S1: The SEM results of the female internet-addicted group. Table S2: Bootstrapping indirect effects and $95 \%$ confidence interval $(\mathrm{CI})$ for the model pathways in the female internet-addicted group.

Author Contributions: X.D. designed and performed the experiments. X.D., R.Z., S.Z. (Simon Zhornitsky) and S.Z. (Sheng Zhang) analyzed the results. X.D., R.Z., S.Z. (Simon Zhornitsky), T.M.L., W.W., C.-S.R.L. and S.Z. (Sheng Zhang) wrote the paper. S.Z. (Sheng Zhang) and C.-S.R.L. supervised, conceived and analyzed the results. All authors have read and agreed to the published version of the manuscript.

Funding: This study was supported by Shaanxi counselor-assisted growth of adolescent's research and the Xi'an Social Science Planning fund project (JY19) to X.D. The funding agencies otherwise had no role in the conceptualization of the study, data collection and analysis or the decision to publish these results. S.Z. (Sheng Zhang) was supported by NIH grant K25DA040032.

Institutional Review Board Statement: The Ethics Committee of Shaanxi University of Science and Technology approved all study procedures. All participants gave their informed consent and parental or guardian consent was obtained for students under 18 years prior to the study.

Informed Consent Statement: Informed consent was obtained from all subjects involved in the study.

Data Availability Statement: Research data are not shared.

Conflicts of Interest: The authors declare no conflict of interest.

\section{References}

1. Naseri, L.; Mohamadi, J.; Sayehmiri, K.; Azizpoor, Y. Perceived Social Support, Self-Esteem, and Internet Addiction Among Students of Al-Zahra University, Tehran, Iran. Iran J. Psychiatry Behav. Sci. 2015, 9, e421. [CrossRef] [PubMed]

2. Kim, K.; Ryu, E.; Chon, M.Y.; Yeun, E.-J.; Choi, S.-Y.; Seo, J.S.; Nam, B.W. Internet addiction in Korean adolescents and its relation to depression and suicidal ideation: A questionnaire survey. Int. J. Nurs. Stud. 2006, 43, 185-192. [CrossRef] [PubMed]

3. Fu, K.W.; Chan, W.S.; Wong, P.W.; Yip, P.S. Internet addiction: Prevalence, discriminant validity and correlates among adolescents in Hong Kong. Br. J. Psychiatry 2010, 196, 486-492. [CrossRef] [PubMed]

4. Wu, C.Y.; Lee, M.-B.; Liao, S.C.; Chang, L.R. Risk Factors of Internet Addiction among Internet Users: An Online Questionnaire Survey. PLoS ONE 2015, 10, e0137506. [CrossRef]

5. Hassan, T.; Alam, M.M.; Wahab, A.; Hawlader, M.D. Prevalence and associated factors of internet addiction among young adults in Bangladesh. J. Egypt Public Health Assoc. 2020, 95, 3. [CrossRef]

6. Ying Ying, C.; Awaluddin, S.M.; Kuang Kuay, L.; Siew Man, C.; Baharudin, A.; Miaw Yn, L.; Sahril, N.; Omar, M.A.; Ahmad, N.A.; Ibrahim, N. Association of Internet Addiction with Adolescents' Lifestyle: A National School-Based Survey. Int. J. Environ. Res. Public Health 2021, 18, 168. [CrossRef]

7. Young, K.S. Psychology of computer use: XL. Addictive use of the Internet: A case that breaks the stereotype. Psychol. Rep. 1996, 79, 899-902. [CrossRef] [PubMed]

8. Carli, V.; Durkee, T.; Wasserman, D.; Hadlaczky, G.; Despalins, R.; Kramarz, E.; Wasserman, C.; Sarchiapone, M.; Hoven, C.W.; Brunner, R. The association between pathological internet use and comorbid psychopathology: A systematic review. Psychopathology 2013, 46, 1-13. [CrossRef] [PubMed]

9. Fagiolini, A. Internet Addiction Disorder in a Sample of 402 High School Students. Psychiatr. Pol. 2015, 49, 255-263. [CrossRef] [PubMed]

10. Ko, C.H.; Yen, J.Y.; Yen, C.F.; Chen, C.S.; Chen, C.C. The association between Internet addiction and psychiatric disorder: A review of the literature. Eur. Psychiatry 2012, 27, 1-8. [CrossRef]

11. Lim, J.A.; Gwak, A.R.; Park, S.M.; Kwon, J.G.; Lee, J.Y.; Jung, H.Y.; Sohn, B.K.; Kim, J.W.; Kim, D.J.; Choi, J.S. Are adolescents with internet addiction prone to aggressive behavior? The mediating effect of clinical comorbidities on the predictability of aggression in adolescents with internet addiction. Cyberpsychol. Behav. Soc. Netw. 2015, 18, 260-267. [CrossRef] [PubMed]

12. Chaudhury, P.; Tripathy, H.K. A Study on impact of smartphone addiction on academic performance. Int. J. Eng. Technol. 2018, 7, 50-53. [CrossRef]

13. Holden, C. Behavioral addictions: Do they exist? Science 2001, 294, 980-982. [CrossRef]

14. Valentini, M.; Biondi, M. The emergence of behavioral addictions. Riv. Psichiatr. 2016, 51, 85-86. [PubMed]

15. Zhang, J.T.; Ma, S.S.; Li, C.S.R.; Liu, L.; Xia, C.C.; Lan, J.; Wang, L.J.; Liu, B.; Yao, Y.W.; Fang, X.Y. Craving behavioral intervention for internet gaming disorder: Remediation of functional connectivity of the ventral striatum. Addict. Biol. 2018, 23, 337-346. [CrossRef]

16. Schramm-Sapyta, N.L.; Walker, Q.D.; Caster, J.M.; Levin, E.D.; Kuhn, C.M. Are adolescents more vulnerable to drug addiction than adults? Evidence from animal models. Psychopharmacology 2009, 206, 1-21. [CrossRef] 
17. Corongiu, S.; Dessi, C.; Cadoni, C. Adolescence versus adulthood: Differences in basal mesolimbic and nigrostriatal dopamine transmission and response to drugs of abuse. Addict. Biol. 2020, 25, e12721. [CrossRef]

18. Şaşmaz, T.; Öner, S.; Kurt, A.Ö.; Yapıc1, G.; Yazıc1, A.E.; Buğdaycı, R.; Şiş, M. Prevalence and risk factors of Internet addiction in high school students. Eur. J. Public Health 2014, 24, 15-20. [CrossRef]

19. Ma, S.S.; Li, C.S.R.; Zhang, S.; Worhunsky, P.D.; Zhou, N.; Zhang, J.T.; Liu, L.; Yao, Y.W.; Fang, X.Y. Altered functional network activities for behavioral adjustments and Bayesian learning in young men with Internet gaming disorder. J. Behav. Addict. 2021, 10, 112-122. [CrossRef]

20. Yen, J.Y.; Ko, C.H.; Yen, C.F.; Chen, S.H.; Chung, W.L.; Chen, C.C. Psychiatric symptoms in adolescents with Internet addiction: Comparison with substance use. Psychiatry Clin. Neurosci. 2008, 62, 9-16. [CrossRef] [PubMed]

21. Suler, J.R. To get what you need: Healthy and pathological internet use. Cyberpsychol. Behav. 1999, 2, 385-393. [CrossRef] [PubMed]

22. Tsitsika, A.; Critselis, E.; Kormas, G.; Filippopoulou, A.; Tounissidou, D.; Freskou, A.; Spiliopoulou, T.; Louizou, A.; Konstantoulaki, E.; Kafetzis, D. Internet use and misuse: A multivariate regression analysis of the predictive factors of internet use among Greek adolescents. Eur. J. Pediatr. 2009, 168, 655-665. [CrossRef] [PubMed]

23. Valkenburg, P.M.; Peter, J. Online Communication and Adolescent Well-Being: Testing the Stimulation Versus the Displacement Hypothesis. J. Comput. Mediat. Commun. 2007, 12, 1169-1182. [CrossRef]

24. Hesapçığlu, S.; Yeşilova, H. Internet addiction prevalence in youths and its relation with depressive symptoms, self-esteem, and bullying. Anatol. J. Psychiatry 2020, 1, 483-490. [CrossRef]

25. Liu, L.; Yao, Y.W.; Li, C.-s.R.; Zhang, J.T.; Xia, C.C.; Lan, J.; Ma, S.S.; Zhou, N.; Fang, X.Y. The Comorbidity Between Internet Gaming Disorder and Depression: Interrelationship and Neural Mechanisms. Front. Psychiatry 2018, 9, 154. [CrossRef]

26. Tucci, A.M.; Kerr-Corrêa, F.; Souza-Formigoni, M.L. Childhood trauma in substance use disorder and depression: An analysis by gender among a Brazilian clinical sample. Child Abus. Negl. 2010, 34, 95-104. [CrossRef]

27. Mandelli, L.; Petrelli, C.; Serretti, A. The role of specific early trauma in adult depression: A meta-analysis of published literature. Childhood trauma and adult depression. Eur. Psychiatry 2015, 30, 665-680. [CrossRef]

28. Heim, C.; Newport, D.J.; Mletzko, T.; Miller, A.H.; Nemeroff, C.B. The link between childhood trauma and depression: Insights from HPA axis studies in humans. Psychoneuroendocrinology 2008, 33, 693-710. [CrossRef]

29. Kessler, R.C.; McLaughlin, K.A.; Green, J.G.; Gruber, M.J.; Sampson, N.A.; Zaslavsky, A.M.; Aguilar-Gaxiola, S.; Alhamzawi, A.O.; Alonso, J.; Angermeyer, M. Childhood adversities and adult psychopathology in the WHO World Mental Health Surveys. Br. J. Psychiatry 2010, 197, 378-385. [CrossRef]

30. Wu, N.S.; Schairer, L.C.; Dellor, E.; Grella, C. Childhood trauma and health outcomes in adults with comorbid substance abuse and mental health disorders. Addict. Behav. 2010, 35, 68-71. [CrossRef]

31. Briere, J.; Woo, R.; McRae, B.; Foltz, J.; Sitzman, R. Lifetime victimization history, demographics, and clinical status in female psychiatric emergency room patients. J. Nerv. Ment. Dis. 1997, 185, 95-101. [CrossRef]

32. Silverman, A.B.; Reinherz, H.Z.; Giaconia, R.M. The long-term sequelae of child and adolescent abuse: A longitudinal community study. Child. Abuse Negl. 1996, 20, 709-723. [CrossRef]

33. Zhang, Z.H.; Yang, L.; Hao, J.; Huang, F.; Zhang, X.; Sun, Y. Relationship of childhood physical abuse and internet addiction disorder in adolescence: The mediating role of self-esteem. Zhonghua Liu Xing Bing Xue Za Zhi 2012, 33, 50-53.

34. Hsieh, Y.P.; Shen, A.C.T.; Wei, H.S.; Feng, J.Y.; Huang, S.C.Y.; Hwa, H.L. Associations between child maltreatment, PTSD, and internet addiction among Taiwanese students. Comput. Hum. Behav. 2016, 56, 209-214. [CrossRef]

35. Kircaburun, K.; Griffiths, M.D.; Billieux, J. Psychosocial factors mediating the relationship between childhood emotional trauma and internet gaming disorder: A pilot study. Eur. J. Psychotraumatol. 2019, 10, 1565031. [CrossRef] [PubMed]

36. Wang, Z.; Xie, Q.; Xin, M.; Wei, C.; Yu, C.; Zhen, S.; Liu, S.; Wang, J.; Zhang, W. Cybervictimization, Depression, and Adolescent Internet Addiction: The Moderating Effect of Prosocial Peer Affiliation. Front. Psychol. 2020, 11, 572486. [CrossRef] [PubMed]

37. Zhao, F.; Zhang, Z.H.; Bi, L.; Wu, X.S.; Wang, W.J.; Li, Y.F.; Sun, Y.H. The association between life events and internet addiction among Chinese vocational school students: The mediating role of depression. Comput. Hum. Behav. 2017, 70, 30-38. [CrossRef]

38. Schimmenti, A.; Passanisi, A.; Caretti, V.; La Marca, L.; Granieri, A.; Iacolino, C.; Gervasi, A.M.; Maganuco, N.R.; Billieux, J. Traumatic experiences, alexithymia, and Internet addiction symptoms among late adolescents: A moderated mediation analysis. Addict. Behav. 2017, 64, 314-320. [CrossRef]

39. Yates, T.M.; Gregor, M.A.; Haviland, M.G. Child maltreatment, alexithymia, and problematic internet use in young adulthood. Cyberpsychol. Behav. Soc. Netw. 2012, 15, 219-225. [CrossRef] [PubMed]

40. Shi, L.; Wang, Y.; Yu, H.; Wilson, A.; Cook, S.; Duan, Z.; Peng, K.; Hu, Z.; Ou, J.; Duan, S. The relationship between childhood trauma and Internet gaming disorder among college students: A structural equation model. J. Behav. Addict. 2020, 9, 175-180. [CrossRef]

41. Dong, G.; Wang, L.; Du, X.; Potenza, M.N. Gender-related differences in neural responses to gaming cues before and after gaming: Implications for gender-specific vulnerabilities to Internet gaming disorder. Soc. Cogn. Affect. Neurosci. 2018, 13, $1203-1214$. [CrossRef] [PubMed]

42. Oflu, A.; Yalcin, S.S. Video game use among secondary school students and associated factors. Arch. Argent. Pediatr. 2019, 117, e584-e591. 
43. Shek, D.T.; Yu, L. Adolescent Internet Addiction in Hong Kong: Prevalence, Change, and Correlates. J. Pediatr. Adolesc. Gynecol. 2016, 29 (Suppl. 1), S22-S30. [CrossRef] [PubMed]

44. Hong, F.-Y.; Chiu, S.-I.; Huang, D.-H. A model of the relationship between psychological characteristics, mobile phone addiction and use of mobile phones by Taiwanese university female students. Comput. Hum. Behav. 2012, 28, 2152-2159. [CrossRef]

45. Walsh, S.P.; White, K.M.; Cox, S.; Young, R.M. Keeping in constant touch: The predictors of young Australians' mobile phone involvement. Comput. Hum. Behav. 2011, 27, 333-342. [CrossRef]

46. Yen, J.-Y.; Yen, C.F.; Chen, C.S.; Tang, T.C.; Ko, C.H. The association between adult ADHD symptoms and internet addiction among college students: The gender difference. Cyberpsychol. Behav. 2009, 12, 187-191. [CrossRef] [PubMed]

47. Ha, Y.-M.; Hwang, W.J. Gender Differences in Internet Addiction Associated with Psychological Health Indicators Among Adolescents Using a National Web-based Survey. Int. J. Ment. Health Addict. 2014, 12, 660-669. [CrossRef]

48. McGuinness, T.M.; Dyer, J.G.; Wade, E.H. Gender differences in adolescent depression. J. Psychosoc. Nurs. Ment. Health Serv. 2012, 50, 17-20. [CrossRef] [PubMed]

49. Angst, J.; Gamma, A.; Gastpar, M.; Lépine, J.-P.; Mendlewicz, J.; Tylee, A. Gender differences in depression. Epidemiological findings from the European DEPRES I and II studies. Eur. Arch. Psychiatry Clin. Neurosci. 2002, 252, 201-209. [CrossRef] [PubMed]

50. Jelenchick, L.A.; Becker, T.; Moreno, M.A. Assessing the psychometric properties of the Internet Addiction Test (IAT) in US college students. Psychiatry Res. 2012, 196, 296-301. [CrossRef] [PubMed]

51. Khazaal, Y.; Billieux, J.; Thorens, G.; Khan, R.; Louati, Y.; Scarlatti, E.; Theintz, F.; Lederrey, J.; Van Der Linden, M.; Zullino, D. French validation of the internet addiction test. Cyberpsychol. Behav. 2008, 11, 703-706. [CrossRef] [PubMed]

52. Barke, A.; Nyenhuis, N.; Kroner-Herwig, B. The German version of the internet addiction test: A validation study. Cyberpsychol. Behav. Soc. Netw. 2012, 15, 534-542. [CrossRef] [PubMed]

53. Hawi, N.S.; Blachnio, A.; Przepiorka, A. Polish validation of the Internet Addiction Test. Comput. Hum. Behav. 2015, 48, 548-553. [CrossRef]

54. Fernández-Villa, T.; Molina, A.J.; García-Martín, M.; Llorca, J.; Delgado-Rodríguez, M.; Martín, V. Validation and psychometric analysis of the Internet Addiction Test in Spanish among college students. BMC Public Health 2015, 15, 953. [CrossRef]

55. Tsimtsiou, Z.; Haidich, A.-B.; Kokkali, S.; Dardavesis, T.; Young, K.S.; Arvanitidou, M. Greek version of the Internet Addiction Test: A validation study. Psychiatr. Q. 2014, 85, 187-195. [CrossRef]

56. Hawi, N.S. Arabic validation of the Internet addiction test. Cyberpsychol. Behav. Soc. Netw. 2013, 16, 200-204. [CrossRef]

57. Tran, B.X.; Mai, H.T.; Nguyen, L.H.; Nguyen, C.T.; Latkin, C.A.; Zhang, M.W.; Ho, R.C. Vietnamese validation of the short version of Internet Addiction Test. Addict. Behav. Rep. 2017, 6, 45-50. [CrossRef] [PubMed]

58. Siste, K.; Suwartono, C.; Nasrun, M.W.; Bardosono, S.; Sekartini, R.; Pandelaki, J.; Sarasvita, R.; Murtani, B.J.; Damayanti, R.; Wiguna, T. Validation study of the Indonesian internet addiction test among adolescents. PLoS ONE 2021, 16, e0245833. [CrossRef]

59. Dhir, A.; Chen, S.; Nieminen, M. Psychometric Validation of Internet Addiction Test With Indian Adolescents. J. Educ. Comput. Res. 2015, 53, 15-31. [CrossRef]

60. Waqas, A.; Farooq, F.; Raza, M.; Javed, S.T.; Khan, S.; Ghumman, M.E.; Naveed, S.; Haddad, M. Validation of the Internet Addiction Test in Students at a Pakistani Medical and Dental School. Psychiatr. Q. 2018, 89, 235-247. [CrossRef] [PubMed]

61. Neelapaijit, A.; Pinyopornpanish, M.; Simcharoen, S.; Kuntawong, P.; Wongpakaran, N.; Wongpakaran, T. Psychometric properties of a Thai version internet addiction test. BMC Res. Notes 2018, 11, 69. [CrossRef] [PubMed]

62. Lee, K.; Lee, H.K.; Gyeong, H.; Yu, B.; Song, Y.M.; Kim, D. Reliability and validity of the Korean version of the internet addiction test among college students. J. Korean Med. Sci. 2013, 28, 763-768. [CrossRef] [PubMed]

63. Lai, C.M.; Mak, K.K.; Watanabe, H.; Ang, R.P.; Pang, J.S.; Ho, R.C. Psychometric properties of the internet addiction test in Chinese adolescents. J. Pediatric Psychol. 2013, 38, 794-807. [CrossRef] [PubMed]

64. Moon, S.J.; Hwang, J.S.; Kim, J.Y.; Shin, A.L.; Bae, S.M.; Kim, J.W. Psychometric properties of the Internet Addiction Test: A systematic review and meta-analysis. Cyberpsychol. Behav. Soc. Netw. 2018, 21, 473-484. [CrossRef] [PubMed]

65. Boysan, M.; Kuss, D.J.; Barut, Y.; Ayköse, N.; Güleç, M.; Özdemir, O. Psychometric properties of the Turkish version of the Internet Addiction Test (IAT). Addict. Behav. 2017, 64, 247-252. [CrossRef]

66. Ngai, S.S.-Y. Exploring the Validity of the Internet Addiction Test for Students in Grades 5-9 in Hong Kong. Int. J. Adolesc. Youth 2007, 13, 221-237. [CrossRef]

67. Young, K.S. Internet Addiction: The Emergence of a New Clinical Disorder. CyberPsychol. Behav. 1998, 1, 237-244. [CrossRef]

68. Young, K. Internet Addiction Test for Families (IAT-F). Stoelting, 2017.

69. Young, K.S. Caught in the Net: How to Recognize the Signs of Internet Addiction-And a Winning Strategy for Recovery. John Wiley \& Sons: Hoboken, NJ, USA, 1998.

70. Bernstein, D.P.; Fink, L.; Handelsman, L.; Foote, J.; Lovejoy, M.; Wenzel, K.; Sapareto, E.; Ruggiero, J. Initial reliability and validity of a new retrospective measure of child abuse and neglect. Am. J. Psychiatry 1994, 151, 1132-1136.

71. Paivio, S.C.; Cramer, K.M. Factor structure and reliability of the Childhood Trauma Questionnaire in a Canadian undergraduate student sample. Child Abus. Negl. 2004, 28, 889-904. [CrossRef]

72. Beck, A.T.; Steer, R.A.; Ball, R.; Ranieri, W.F. Comparison of Beck Depression Inventories -IA and -II in psychiatric outpatients. J. Personal. Assess. 1996, 67, 588-597. [CrossRef]

73. Al-Musawi, N.M. Psychometric properties of the beck depression inventory-II with university students in Bahrain. J. Personal. Assess. 2001, 77, 568-579. [CrossRef] 
74. MacKinnon, D.P.; Fairchild, A.J.; Fritz, M.S. Mediation analysis. Annu. Rev. Psychol. 2007, 58, 593-614. [CrossRef]

75. Henseler, J.; Ringle, C.M.; Sarstedt, M. A new criterion for assessing discriminant validity in variance-based structural equation modeling. J. Acad. Mark. Sci. 2014, 43, 115-135. [CrossRef]

76. Williams, L.J.; Hartman, N.; Cavazotte, F. Method Variance and Marker Variables: A Review and Comprehensive CFA Marker Technique. Organ. Res. Methods 2010, 13, 477-514. [CrossRef]

77. Brand, M.; Laier, C.; Young, K.S. Internet addiction: Coping styles, expectancies, and treatment implications. Front. Psychol. 2014, 5, 1256. [CrossRef]

78. Mo, P.K.; Chan, V.W.; Wang, X.; Lau, J.T. Gender difference in the association between internet addiction, self-esteem and academic aspirations among adolescents: A structural equation modelling. Comput. Educ. 2020, 155, 103921. [CrossRef]

79. Park, J.A.; Park, M.H.; Shin, J.H.; Li, B.; Rolfe, D.T.; Yoo, J.Y.; Dittmore, S.W. Effect of sports participation on Internet addiction mediated by self-control: A case of Korean adolescents. Kasetsart J. Soc. Sci. 2016, 37, 164-169. [CrossRef]

80. Dalbudak, E.; Evren, C.; Aldemir, S.; Evren, B. The severity of Internet addiction risk and its relationship with the severity of borderline personality features, childhood traumas, dissociative experiences, depression and anxiety symptoms among Turkish university students. Psychiatry Res. 2014, 219, 577-582. [CrossRef] [PubMed]

81. Evren, C. Severity of dissociative experiences and emotion dysregulation mediate the relationship between childhood trauma and Internet addiction symptom severity among young adults. Dusunen Adam J. Psychiatry Neurol. Sci. 2019, 32, 334-344. [CrossRef]

82. Petry, N.M.; Steinberg, K.L. Childhood maltreatment in male and female treatment-seeking pathological gamblers. Psychol. Addict. Behav. 2005, 19, 226-229. [CrossRef]

83. Magnusson, Å.; Lundholm, C.; Göransson, M.; Copeland, W.; Heilig, M.; Pedersen, N. Familial influence and childhood trauma in female alcoholism. Psychol. Med. 2012, 42, 381-389. [CrossRef]

84. Widom, C.S.; Marmorstein, N.R.; White, H.R. Childhood victimization and illicit drug use in middle adulthood. Psychol. Addict. Behav. 2006, 20, 394-403. [CrossRef] [PubMed]

85. Widom, C.S.; DuMont, K.; Czaja, S.J. A prospective investigation of major depressive disorder and comorbidity in abused and neglected children grown up. Arch. Gen. Psychiatry 2007, 64, 49-56. [CrossRef] [PubMed]

86. Lim, M.S.M.; Cheung, F.Y.L.; Kho, J.M.; Tang, C.K. Childhood adversity and behavioural addictions: The mediating role of emotion dysregulation and depression in an adult community sample. Addict. Res. Theory 2020, 28, 116-123. [CrossRef]

87. Pan, Y.; Lin, X.; Liu, J.; Zhang, S.; Zeng, X.; Chen, F.; Wu, J. Prevalence of Childhood Sexual Abuse Among Women Using the Childhood Trauma Questionnaire: A Worldwide Meta-Analysis. Trauma Violence Abus. 2020. [CrossRef]

88. Loxton, D.; Forder, P.M.; Cavenagh, D.; Townsend, N.; Holliday, E.; Chojenta, C.; Melka, A.S. The impact of adverse childhood experiences on the health and health behaviors of young Australian women. Child Abus. Negl. 2021, 111, 104771. [CrossRef]

89. Wan, G.; Tang, S.; Xu, Y. The prevalence, posttraumatic depression and risk factors of domestic child maltreatment in rural China: A gender analysis. Child. Youth Serv. Rev. 2020, 116, 105266. [CrossRef]

90. Li, S.; Zhao, F.; Yu, G. Childhood Emotional Abuse and Depression Among Adolescents: Roles of Deviant Peer Affiliation and Gender. J. Interpers. Violence 2020. [CrossRef]

91. Villalba, K.; Attonito, J.; Jean-Gilles, M.; Rosenberg, R.; Sanchez, M.; Devieux, J. The effects of childhood sexual abuse: The role of anxiety and alcohol use among Haitian women living with HIV. J. Child Sex. Abus. 2020, 29, 788-801. [CrossRef]

92. Liang, L.; Zhou, D.; Yuan, C.; Shao, A.; Bian, Y. Gender differences in the relationship between internet addiction and depression: A cross-lagged study in Chinese adolescents. Comput. Hum. Behav. 2016, 63, 463-470. [CrossRef]

93. Ko, C.H.; Liu, T.L.; Wang, P.W.; Chen, C.S.; Yen, C.F.; Yen, J.Y. The exacerbation of depression, hostility, and social anxiety in the course of Internet addiction among adolescents: A prospective study. Compr. Psychiatry 2014, 55, 1377-1384. [CrossRef]

94. Kessler, R.C.; McGonagle, K.A.; Zhao, S.; Nelson, C.B.; Hughes, M.; Eshleman, S.; Wittchen, H.U.; Kendler, K.S. Lifetime and 12-Month Prevalence of DSM-III-R Psychiatric Disorders in the United States: Results From the National Comorbidity Survey. Arch. Gen. Psychiatry 1994, 51, 8-19. [CrossRef] [PubMed]

95. Nolen-Hoeksema, S. Sex differences in unipolar depression: Evidence and theory. Psychol. Bull. 1987, 101, 259-282. [CrossRef] [PubMed]

96. Weissman, M.M.; Bland, R.C.; Canino, G.J.; Faravelli, C.; Greenwald, S.; Hwu, H.G.; Joyce, P.R.; Karam, E.G.; Lee, C.K.; Lellouch, J. Cross-National Epidemiology of Major Depression and Bipolar Disorder. JAMA 1996, 276, 293-299. [CrossRef] [PubMed]

97. Wade, T.J.; Cairney, J.; Pevalin, D.J. Emergence of Gender Differences in Depression During Adolescence: National Panel Results From Three Countries. J. Am. Acad. Child Adolesc. Psychiatry 2002, 41, 190-198. [CrossRef] [PubMed]

98. Bouma, E.M.; Ormel, J.; Verhulst, F.C.; Oldehinkel, A.J. Stressful life events and depressive problems in early adolescent boys and girls: The influence of parental depression, temperament and family environment. J. Affect. Disord. 2008, 105, 185-193. [CrossRef] [PubMed]

99. Gallo, E.A.G.; Munhoz, T.N.; de Mola, C.L.; Murray, J. Gender differences in the effects of childhood maltreatment on adult depression and anxiety: A systematic review and meta-analysis. Child Abus. Negl. 2018, 79, 107-114. [CrossRef]

100. Garcia, M.; Munhoz, T.N.; de Mola, C.L.; Murray, J. Sex differences in the effect of childhood trauma on the clinical expression of early psychosis. Compr. Psychiatry 2016, 68, 86-96. [CrossRef]

101. Sweeney, S.; Air, T.; Zannettino, L.; Shah, S.S.; Galletly, C. Gender Differences in the Physical and Psychological Manifestation of Childhood Trauma and/or Adversity in People with Psychosis. Front. Psychol. 2015, 6, 1768. [CrossRef] [PubMed] 
102. Şar, V.; Türk, T.; Öztürk, E. Fear of happiness among college students: The role of gender, childhood psychological trauma, and dissociation. Indian J. Psychiatry 2019, 61, 389-394. [CrossRef]

103. Simpson, J.L.; Grant, K.M.; Daly, P.M.; Kelley, S.G.; Carlo, G.; Bevins, R.A. Psychological Burden and Gender Differences in Methamphetamine-Dependent Individuals in Treatment. J. Psychoact. Drugs 2016, 48, 261-269. [CrossRef] [PubMed]

104. Marotta, P.L. Childhood Adversities and Substance Misuse Among the Incarcerated: Implications for Treatment and Practice in Correctional Settings. Subst. Use Misuse 2017, 52, 717-733. [CrossRef]

105. Zhornitsky, S.; Le, T.M.; Dhingra, I.; Adkinson, B.D.; Potvin, S.; Li, C.s.R. Interpersonal Risk Factors for Suicide in Cocaine Dependence: Association with Self-Esteem, Personality Traits, and Childhood Abuse. Suicide Life Threat. Behav. 2020, 50, 867-883. [CrossRef] [PubMed]

106. Li, X.; Wang, Z.; Hou, Y.; Wang, Y.; Liu, J.; Wang, C. Effects of childhood trauma on personality in a sample of Chinese adolescents. Child Abus. Negl. 2014, 38, 788-796. [CrossRef] [PubMed]

107. Liang, Y.; Zhou, Y.; Ruzek, J.I.; Liu, Z. Patterns of childhood trauma and psychopathology among Chinese rural-to-urban migrant children. Child Abus. Negl. 2020, 108, 104691. [CrossRef]

108. Wang, M.; Liu, L. Reciprocal Relations Between Harsh Discipline and Children's Externalizing Behavior in China: A 5-Year Longitudinal Study. Child Dev. 2018, 89, 174-187. [CrossRef]

109. Choi, K.; Son, H.; Park, M.; Han, J.; Kim, K.; Lee, B.; Gwak, H. Internet overuse and excessive daytime sleepiness in adolescents. Psychiatry Clin. Neurosci. 2009, 63, 455-462. [CrossRef]

110. Kawabe, K.; Horiuchi, F.; Ochi, M.; Oka, Y.; Ueno, S.I. Internet addiction: Prevalence and relation with mental states in adolescents. Psychiatry Clin. Neurosci. 2016, 70, 405-412. [CrossRef]

111. Ni, X.; Yan, H.; Chen, S.; Liu, Z. Factors influencing internet addiction in a sample of freshmen university students in China. Cyberpsychol. Behav. 2009, 12, 327-330. [CrossRef] [PubMed] 